A zero value had been found in all cases before tamoxifen treatment, but after tamoxifen the index regularly increased to values between 10 and $30 \%$, reaching $50 \%$ or more in four cases and $80 \%$ in one. This effect has not previously been described in humans. The smears returned to an atrophic pattern within two months after tamoxifen withdrawal. Overall, $32 \%$ of the patients responded favourably to tamoxifen, showing an objective tumour regression.

No sure relationship has been evidenced between the post-treatment rise in KPI and the response of cancer to tamoxifen treatment. As in some animal models, the drug seems to have an oestrogen-like effect on the vaginal epithelium. It is still not clear whether the tumour may also react to tamoxifen as if it was an oestrogen.

E FerRAZZi G CARTEI

R MATTARAZZO M FIORENTINO

Department of Medical Oncology, Regional General Hospital, Padua, Italy

${ }^{1}$ Clarke, J H, Peck, E, jun, and Anderson, J N, Nature, $1974,251,446$. 1974, 251, 446.
2 Harper, H J K, and Walpole, A L, Nature, 1967, 87,
212 .

3 Jordan, V C, European fournal of Cancer, 1976, 12,

- Skidmore, J, Walpole, A L, and Woodburn, J, Fournal of Endocrinology, 1972, 52, 289.

\section{Royal College of Physicians and} fluoridation

SIR,-The selective use of research material from studies by Dr Robert Weaver quoted by the authors of the Royal College of Physicians report Fluoride, Teeth and Health ${ }^{1}$ is surprising and merits explanation.

On $\mathrm{p} 9$ of their report they refer to a paper published by Dr Weaver" showing that 5-yearold children in South Shields with naturally fluoridated water at $1.4 \mathrm{ppm}$ had on average 3.9 decayed, missing, or filled (DMF) teeth compared with 6.6 in children in North Shields with 0.25 ppm fluoride in the drinking water. Moreover, says the report, "at the age of 12 the number of DMF teeth in South Shields was $56^{\circ}$ of that in North Shields."

In Weaver's second study" evidence was given "which suggests that fluorine is a caries-postponing rather than a caries-preventing factor." Table III of this paper shows that by the age of 15 years children from South Shields had an average of $4.4 \mathrm{DMF}$ teeth compared with 4.3 at the age of 12 years in North Shields. By the age of 17 those in the high-fluoride areas had 6.5 DMF teeth compared with 7.2 in the low-fluoride areas, a difference of about half a decayed tooth on average and a difference which steadily lessens with increasing age. A survey to discover if the effects of water-borne fluorides continued into adulthood showed that young South Shields mothers had a dental advantage of about five years, but for the over-30s the difference was negligible.

Dr Weaver's third paper, ${ }^{4}$ also unmentioned in the RCP's report, contains his final and considered conclusions in which it was shown that "only a limited effect could be expected from the ingestion of fluoride in drinking water." Weaver remarked that if the protection given by fluorine in South Shields had not been shown to be of brief duration the dental profession would have been faced with an embarrassing question, which would have been, "If the incidence of dental caries in South Shields is so very much less than in North Shields, why is it that the population of South Shields is no healthier than that of North Shields? The answer is that the figure of $56^{\circ}$ o which I have given in connection with the findings in 12-year-old children is misleading. There is no very striking difference in the incidence of caries in the two towns."

Perhaps the authors of Fluoride, Teeth and Health would care to explain why they omitted these important statements and conclusions from one of their own references.

RONALD V MUMMERY

St Helier,

' Royal College of Physicians of London, Fluoride, Teeth and Health. London, Pitman, 1976. 2 Weaver, R, British Dental fournal, 1944, 76, 29. - Weaver, R, British Dental fournal, 1944, 77, 185. Meaver, R, Proceedings of the Royal Society of
Medicine, 1948, 41, 284.

\section{Academics and scientists}

SIR,-It appears that Dr W B Hepburn chose to use the rather inappropriate medium of a book review (9 April, p 966) to air his individual prejudices. It is particularly difficult to understand why he felt it necessary to introduce an unrecognisable character sketch of the late Professor $\mathrm{H}$ A Harris into a review of a series of biographies which did not include him.

The strength of $\mathrm{H}$ A Harris's personality would have demanded deference, whatever had been his academic status, and I am sure that there can be few who knew him who would find "quaint" an appropriate descriptive adjective. While far from a midget in physical stature H A Harris was of a mental stature such as to inspire the respect, admiration, and eventually affection of many of his students and staff. Without the very real inspiration provided by him and his department the current shortage of medically qualified anatomists would have been even more desperate than it is. Among all the positive features of H A Harris's character it is regrettable that Dr Hepburn chose only to select two of his antipathies-whistling and under graduate arrogance.

DAvid BulMER

Medical and Biologica

Sciences Building,

University of Southampton

\section{Parascending: a safer alternative to hang} gliding

SIR,-Dr G M Youill's presentation of the risks of hang gliding (26 March, p 823) complements Kirby's report on parachuting from aircraft. ${ }^{1}$ The purpose of this letter is to draw attention to the existence of a third much less dangerous aerial sport called parascending (parasailing in the USA). It is probably the simplest, cheapest, and safest way for the individual to get into the air. The parascender puts on the parachute harness with the canopy laid out behind him. A tow-line (usually $460 \mathrm{~m} \mathrm{(500} \mathrm{yards)} \mathrm{long}$ for the trained club member) from the harness is hitched to a Land Rover, which moves off at a speed appropriate to the wind conditions and the weight of the parascender. The parachute, held open by two wing-tip holders, inflates and the parascender goes up like a glider. At the desired height of $250-300 \mathrm{~m}$ (800-1000 feet) the parascender releases himself from the tow-line, steers his course, and makes his landing. The flight and landing techniques are the same as in parachuting from aircraft, but the risks of exit and of canopy maldevelopment are abolished; the parascender is not towed up if any fault appears when the canopy is opened on the ground.

The British Association of Parascending Clubs is the national body concerned with the licensing of instructors and national aspects of the sport. It is closely concerned with all matters of safety. The injury rate for 50807 flights in the USA was reported to be about $0.5 \%,{ }^{2}$ but we consider the risk to be smaller. The injuries we encounter are abrasions, bruises, sprains, and minor undisplaced fractures which do not keep members off work, and even these are unusual outside the competitions which tempt a parascender to go for the target instead of landing defensively. From four club seasons with over 2000 flights two members have been admitted to hospital : one suffered acute pain from a known and previously disabling lumbar disc lesion and the other had a grand mal attack.

This information is presented because we believe that parascending should be dealt with in its own right by insurance underwriters and not classed with hang gliding or parachuting from aircraft.

A J MACAULAY
Chief Instructor
P G F NixoN
President,
Charing Cross Hospital
Parascending Club

Kirby, N G, Proceedings of the Royal Society of Medicine, 1974, 67, 17.
Hall, G W Aviation, Space and Environmental
Medicine, 1977, 48, 164.

\section{Night visiting rates by general practitioners}

SIR,-I wish to comment on the article on this subject by $\mathrm{Mr} M \mathrm{~J}$ Buxton and others from the Centre for Social Studies (26 March, p 827) and Dr I C Gilchrist's letter (7 May; p 1217).

$\mathrm{Mr}$ Buxton and his colleagues record an increase of approximately $135 \%$ in the night visiting rate per 1000 patients between 1967-8 and 1975-6 for the country as a whole. In this group practice of four, by contrast, our night visiting rate in 11 years to 1976 dropped by $15.2 \%$. We recorded our night calls $(11 \mathrm{pm}$ to $8 \mathrm{am}$ ) for six years, 1 January 1960 31 December $1965,{ }^{1}$ and again 11 years later, for 1976. The night call rate for the six years 1960-5 averaged 6.6 and this compares with 5.6 per 1000 patients in 1976 (64 night calls for our list of 11440 ). We considered that only three $(4 \cdot 1 \%)$ of these calls were unnecessary.

The authors speculate on whether the number of night calls has risen since 1967, after which general practitioners began to be paid for these night calls. In this practice they have fallen. They also point out that deputising services and a high proportion of social class $V$ patients increase the night visiting rate. In Farnborough we have our own rota for calls and the number of social class $\mathrm{V}$ patients is low. The figures provided by $\mathrm{Mr}$ Buxton and his colleagues also tend to confirm what other 